Article

\title{
Biotrickling Filtration of Air Contaminated with 1-Butanol
}

\author{
Thomas Schmidt and William A. Anderson * \\ Department of Chemical Engineering, University of Waterloo, Waterloo, ON N2L 3G1, Canada; \\ t4schmid@uwaterloo.ca \\ * Correspondence: wanderson@uwaterloo.ca
}

Received: 27 June 2017; Accepted: 10 August 2017; Published: 15 August 2017

\begin{abstract}
The removal of high concentrations of 1-butanol in an air stream was evaluated with a biotrickling filter for potential application to an industrial off-gas. Experiments were conducted on a laboratory-scale system, packed with perlite, in a co-current downward mode with constant recycling of water. The performance was monitored for different inlet concentrations and empty bed residence times during a period of over 60 days of stable operation. A maximum elimination capacity (EC) of $100 \mathrm{~g} \mathrm{~m}^{-3} \mathrm{~h}^{-1}$ was achieved during periods in which the butanol concentration varied from 0.55 to $4.65 \mathrm{~g} \mathrm{~m}^{-3}$. The removal efficiency was stable and exceeded $80 \%$ for butanol concentrations in the range of 0.4 to $1.2 \mathrm{~g} \mathrm{~m}^{-3}$, corresponding to inlet mass loadings of up to approximately $100 \mathrm{~g} \mathrm{~m}^{-3} \mathrm{~h}^{-1}$. However, when the concentration exceeded $4 \mathrm{~g} \mathrm{~m}^{-3}$, removal efficiency rapidly dropped to $15 \%$ (EC of $22 \mathrm{~g} \mathrm{~m}^{-3} \mathrm{~h}^{-1}$ ), indicating an inhibition effect that was reversed by decreasing the inlet concentration. This biotrickling filter was able to deal with higher sustained butanol concentrations than have been previously reported, but might not be suitable for concentrations much in excess of $1.2 \mathrm{~g} \mathrm{~m}^{-3}$ or mass inlet loads in excess of $100 \mathrm{~g} \mathrm{~m}^{-3} \mathrm{~h}^{-1}$.
\end{abstract}

Keywords: biotrickling filter; biofiltration; inhibition; solvents; n-butyl alcohol; elimination capacity

\section{Introduction}

The emissions of volatile organic compounds (VOCs) into the environment need to be controlled appropriately to protect or improve local air quality and to minimize tropospheric ozone formation. Although several different technologies are available, biological air treatment has attracted interest, especially for applications with moderate VOC concentrations below $10 \mathrm{~g} \mathrm{~m}^{-3}[1,2]$, because of its potentially favourable economics [3]. In comparison to conventional pollution control technologies, such as absorption, catalytic oxidation, condensation, and incineration, biological air treatment appears to have advantages which include high removal efficiencies, low installation and operating costs, good reliability, stable performance, and applicability to situations with larger volumes of waste gases containing lower concentrations of VOCs. Numerous examples of successful applications in the treatment of VOCs and odours can be found in literature [4-6]. Much of the work has focused on biofiltration, where a humidified gas is routed through a microbe-containing packed bed. Other work has been reported on biotrickling filtration, where a liquid phase continuously flows over an inert packing material that supports the microbial community. Biotrickling filtration has several potential advantages for systems that are difficult to pre-humidify, or that present challenges in $\mathrm{pH}$ and/or temperature control $[7,8]$.

In this work, control of 1-butanol (n-butyl alcohol) was of interest because it was identified as a major component of a local industrial intermittent emission resulting from thermal regeneration of adsorbents, at concentrations in the range of 5 to $10 \mathrm{~g} \mathrm{~m}^{-3}$ or even higher. Studies have been reported in literature with laboratory-scale bioreactors to evaluate the performance for a range of hydrocarbons 
and oxygenated hydrocarbons [9-16]. However, the biological treatment of 1-butanol in air has not been as extensively reported as some other compounds, especially at higher concentrations. Heinze and Friedrich [17] examined 1-butanol biofiltration (not biotrickling) with several different packing materials, but at relatively low concentrations $\left(0.24 \mathrm{~g} \mathrm{~m}^{-3}\right)$. Fitch et al. [18] successfully treated air phase 1-butanol in a membrane bioreactor at concentrations up to approximately $1.1 \mathrm{~g} \mathrm{~m}^{-3}$. Lee et al. [19] treated approximately $4.3 \times 10^{-4} \mathrm{~g} \mathrm{~m}^{-3} 1$-butanol in a gas phase mixture including acetone and ammonia. Ondarts et al. [20] evaluated a compost biofilter operation for a VOC mixture where butanol was present at concentrations up to $1.9 \times 10^{-5} \mathrm{~g} \mathrm{~m}^{-3}$. Chan and Lai [11] studied the interaction between 1-butanol and 2-butanol degradation in polyvinyl alcohol bead-packed biofilters at concentrations up to approximately $1 \mathrm{~g} \mathrm{~m}^{-3}$, noting that 1-butanol inhibited 2-butanol degradation. Feizi et al. [21] tested higher concentrations of n-butanol concentrations (up to $3.2 \mathrm{~g} \mathrm{~m}^{-3}$ ), but only under transient conditions lasting a few hours. One of the only biotrickling filter studies was performed by Wang et al. [22] on a mixture of butyl acetate, butanol and phenyl acetic acid at butanol concentrations up to $2.4 \mathrm{~g} \mathrm{~m}^{-3}$.

Most of these prior studies were performed at concentrations well below those expected in this potential industrial application, and it is known that butanol is inhibitory or toxic to microbes at concentrations above $2 \%$ in liquid phase fermentations [23]. Therefore, the objective of this study was to investigate the removal performance for 1-butanol at higher sustained concentrations than have been reported previously, to determine if a biological treatment technology might be suitable for application under these conditions.

Humidification of the contaminated air was not expected to be feasible in this proposed industrial application, and so a biotrickling filter (BTF) operating mode was chosen whereby an aqueous solution was continuously trickled over the top of the bed where the butanol-contaminated air entered. In this manner, the inlet of the device could be kept moist while also serving to humidify the gases as they travelled down the bed. Biotrickling filters also provide a mechanism for potentially better temperature, $\mathrm{pH}$, and nutrient concentration control than conventional biofilters. Perlite was chosen as the packing for this study due to its good mechanical and non-compactible properties, which were considered important for this specific application. Perlite is a readily available naturally occurring siliceous volcanic rock [24], with a porous surface that has yielded high volumetric elimination capacities in other biofilters and biotrickling filters $[1,14,25]$.

\section{Materials and Methods}

Nutrient-enriched perlite was purchased from a local supplier (Miracle-GroßPerlite 0.04-0.01-0.06 enriched, Scotts Canada Ltd., Mississauga, CA, USA). Material characteristics were reported to be: $0.04 \%$ total $\mathrm{N}, 0.01 \%$ available phosphorus $\left(\mathrm{P}_{2} \mathrm{O}_{5}\right), 0.06 \%$ soluble potash $\left(\mathrm{K}_{2} \mathrm{O}\right), 200 \mathrm{~kg} \mathrm{~m}^{-3}$ bulk density, and near neutral $\mathrm{pH}$. The perlite was screened into two size fractions. In the upper (inlet) $1 / 8$ section of the BTF, only perlite of a diameter greater than $4.7 \mathrm{~mm}$ was used to help prevent plugging of the column in this region where the most biomass growth was expected. The remaining $7 / 8$ section contained perlite with a size between 4.7 and $1.7 \mathrm{~mm}$.

The experimental work was performed using a laboratory-scale biotrickling filter (BTF) as shown in Figure 1, constructed from glass tubing with an internal diameter of $11.5 \mathrm{~cm}$ and a total height of $90 \mathrm{~cm}$. The BTF was equipped with sampling ports to allow sampling of the stream entering and leaving the BTF, as well as five ports (1-5) axially along the medium bed for gas samples and 3 ports $(A-C)$ for packing material samples. The BTF was packed with perlite to a depth of $67 \mathrm{~cm}$, resulting in a working bed volume of $6.9 \mathrm{~L}$. 


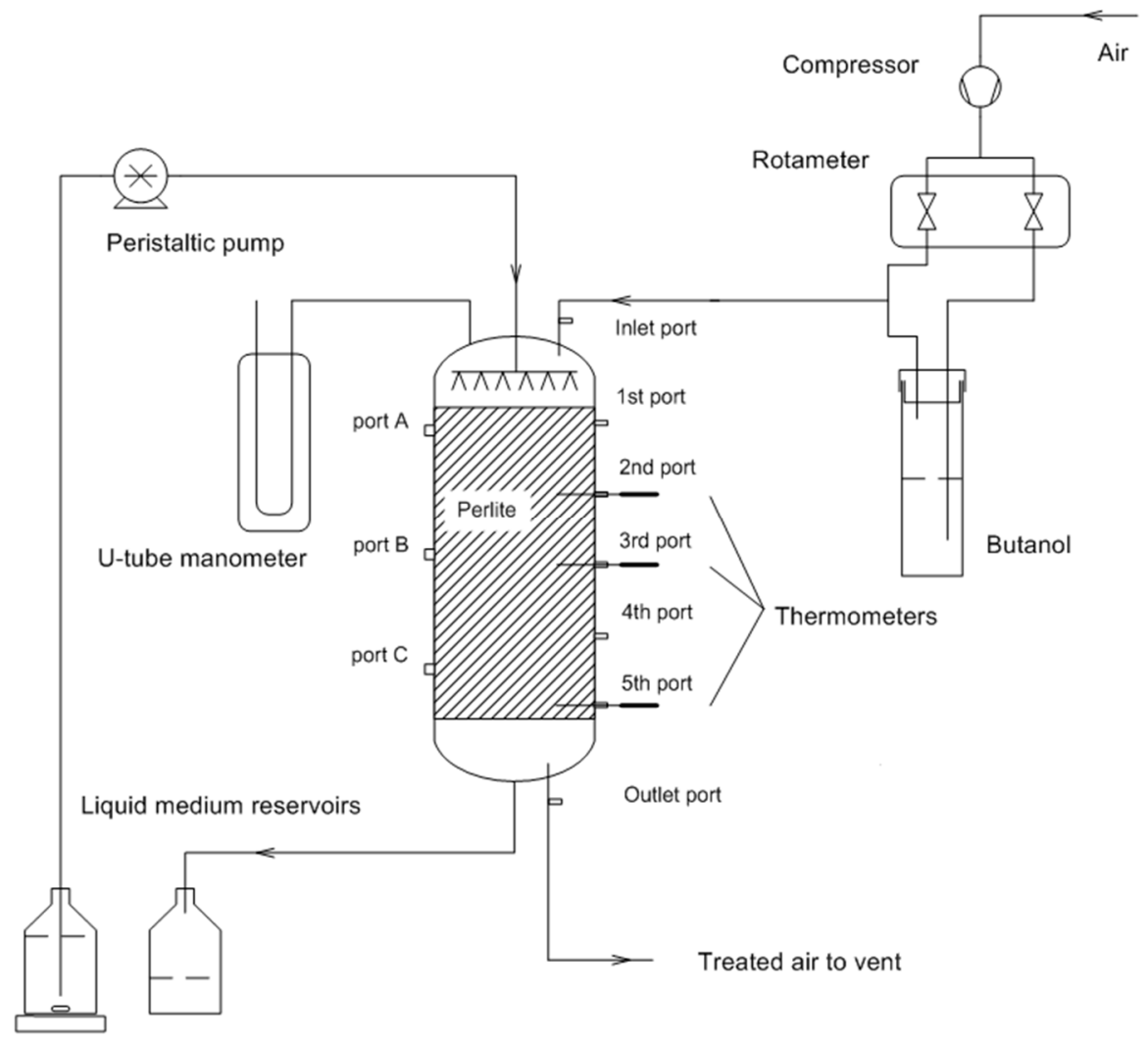

Figure 1. Schematic diagram of the experimental system.

For start-up, a mixed microbial inoculum was prepared and acclimated by placing a sample of a local forest soil in tap water and aerating the solution for 3 days with an air stream containing butanol. Sodium acetate $\left(5 \mathrm{~g} \mathrm{~L}^{-1}\right)$ was added to provide an initial carbon source that was more readily utilized, and a few drops of soybean oil minimized the formation of foam. At start up, the BTF bed was inoculated over a period of $24 \mathrm{~h}$ by recirculation of $2.5 \mathrm{~L}$ of the acclimated solution at a flow rate of $40 \mathrm{~mL} \mathrm{~min}{ }^{-1}$ to distribute microorganisms over all of the packing material. The BTF was operated in a co-current gas and liquid downward flow mode to simplify hydration of the packing in the entrance region where drying tends to occur most rapidly. A continuous flow of water was trickled onto the top of the filter bed through nozzles. The drainage solution was collected at the bottom of the column in a $4 \mathrm{~L}$ vessel and recycled using a peristaltic pump at a flow rate of $40 \mathrm{~mL} \mathrm{~min}^{-1}$. The water was supplemented on several days (27 and 40) with a mineral salt medium consisting of $\left(\mathrm{g} \mathrm{L}^{-1}\right)$ : $\mathrm{Na}_{2} \mathrm{HPO}_{4}$ 3, $\left(\mathrm{NH}_{4}\right)_{2} \mathrm{SO}_{4} 1.5, \mathrm{NH}_{4} \mathrm{Cl} 3, \mathrm{KNO}_{3} 4.5, \mathrm{CaCO}_{3} 1.5, \mathrm{MgSO}_{4} 1.5, \mathrm{~K}_{2} \mathrm{SO}_{4} 1.5$, in deionised water $[6,26]$. The $\mathrm{pH}$ of the solution was neutral and the calcium carbonate served as a buffering material.

The air stream was divided into two, with the smaller stream (approximately 10 to $20 \%$ of the total) directed to a vial where it bubbled through about $10 \mathrm{~cm}$ of liquid butanol maintained at an approximately constant volume. The butanol vapourized into the air stream, and was mixed with the second air stream and introduced into the column. The concentration of butanol in the air stream could be adjusted to the desired value by changing the ratio of the air streams, whereby the total volumetric flow stayed constant. The pressure drop across the packing material was measured by a differential U-tube water manometer connected to the top of the column. The temperature and relative humidity of the air stream was monitored with a thermohygrometer (Oakton, Vernon Hills, IL, USA). The relative humidity of the inlet air ranged between 8 and $10 \%$, while the temperature did not deviate significantly from $23^{\circ} \mathrm{C}$. During the experiments, the inlet gas flowrate (and corresponding empty bed residence time, EBRT) was set at $0.20 \mathrm{~m}^{3} \mathrm{~h}^{-1}$ (days 1 to 6 , EBRT $124 \mathrm{~s}$ ), $0.277 \mathrm{~m}^{3} \mathrm{~h}^{-1}$ (days 7 to 41 , EBRT $90 \mathrm{~s}$ ), $0.415 \mathrm{~m}^{3} \mathrm{~h}^{-1}$ (days 42 to 50, EBRT $60 \mathrm{~s}$ ), and $0.277 \mathrm{~m}^{3} \mathrm{~h}^{-1}$ (final 5 days, EBRT $90 \mathrm{~s}$ ). 
Gas samples for VOC and $\mathrm{CO}_{2}$ analysis were taken with a $1 \mathrm{~mL}$ gas-tight syringe. The concentration of butanol was determined by gas chromatography (GC) (HP 5890 Series II, Agilent, Santa Clara, CA, USA) with a flame ionization detector, using a RTX-502.3 fused silica megabore column of dimensions $30 \mathrm{~m} \times 0.53 \mathrm{~mm}$ and $3 \mu \mathrm{m}$ film thickness. The initial oven temperature was $50{ }^{\circ} \mathrm{C}$ for $3 \mathrm{~min}$, increasing at $20^{\circ} \mathrm{C} \mathrm{min}^{-1}$ to $80^{\circ} \mathrm{C}$ where it was held for $1.5 \mathrm{~min}$. Gas phase samples for $\mathrm{CO}_{2}$ analysis were also taken through the sampling ports at the top and bottom of the BTF. A second GC (HP 5890 Series II) was used for determining the $\mathrm{CO}_{2}$ concentration using He carrier and make-up gas, with a Porapak Q column (Agilent, Santa Clara, CA, USA) at $50{ }^{\circ} \mathrm{C}$ and a thermal conductivity detector.

\section{Results and Discussion}

\subsection{Effect of Gas Flow Rate and Inlet Concentration}

The inlet and outlet concentrations of butanol and the responses of removal efficiency are shown in Figure 2 with respect to time of operation.

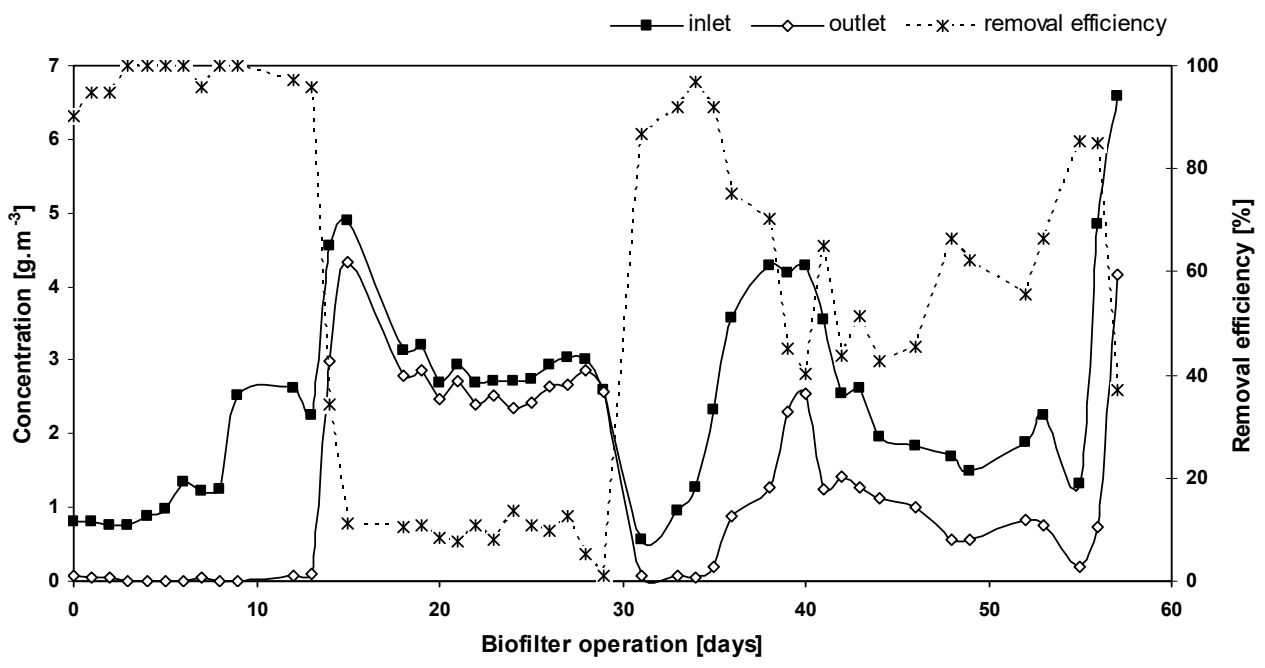

Figure 2. Inlet and outlet butanol concentration in air and removal efficiency during continuous operation of the biotrickling filter (BTF).

After inoculation, the combined effect of butanol inlet concentration and gas flow rate was investigated with respect to removal efficiency and elimination capacities. At start-up, the biotrickling filter (BTF) was run with a butanol inlet concentration of around $0.8 \mathrm{~g} \mathrm{~m}^{-3}$ and an empty bed residence time (EBRT) of $124 \mathrm{~s}$. From Figure 2, it is clear that the BTF had a rapid development of activity after initial start-up. Removal efficiencies of more than $94 \%$ were reached almost immediately, corresponding to an elimination capacity of approximately $20 \mathrm{~g} \mathrm{~m}^{-3} \mathrm{~h}^{-1}$. During the start-up phase, butanol removal might have been due to adsorption on the perlite as the initial biomass concentration was low, but as a biofilm formed over the perlite particles, the removal mechanism must have switched to biodegradation. A similar observation has been reported by Arulneyam et al. [9].

After the sixth day, increasing the inlet concentration to $2.6 \mathrm{~g} \mathrm{~m}^{-3}$ and decreasing the EBRT to $90 \mathrm{~s}$ still resulted in removal efficiencies of at least $96 \%$ being maintained for 7 days, equivalent to an elimination capacity of approximately $100 \mathrm{~g} \mathrm{~m}^{-3} \mathrm{~h}^{-1}$.

The concentrations were subsequently increased to determine the maximum performance of the BTF, and as the butanol concentration exceeded $4 \mathrm{~g} \mathrm{~m}^{-3}$, removal efficiency rapidly decreased. Over the period between day 15 and 29 of operation, the removal efficiency dropped to values lower than $14 \%$, indicating that the filter was overloaded and an inhibition effect of butanol loading might have occurred. Here, the corresponding substrate mass loading rates were in the range of 110 to $120 \mathrm{~g} \mathrm{~m}^{-3} \mathrm{~h}^{-1}$. It is known that exposure to high contaminant loading rates can cause inhibition effects or even kill the microorganisms, 
and a similar decline in performance was observed in other research [15], where it was attributed to inhibition effects at high contaminant concentration as well. Not until the butanol concentration was reduced to values under $1 \mathrm{~g} \mathrm{~m}^{-3}$ and after 13 days of operation, was the removal efficiency restored. However, when high loading rates ( 110 to $120 \mathrm{~g} \mathrm{~m}^{-3} \mathrm{~h}^{-1}$ ) were applied at a constant empty bed residence time of $90 \mathrm{~s}$, the removal efficiency rapidly dropped to near $10 \%$ and then remained almost constant at this low value. Overall, for concentrations lower than $3 \mathrm{~g} \mathrm{~m}^{-3}$, removal efficiencies $>60 \%$ could easily be maintained, but concentrations $>4 \mathrm{~g} \mathrm{~m}^{-3}$ led to a rapid drop in the removal efficiency from $>60$ to $15 \%$.

After day 41, the EBRT was further reduced to $60 \mathrm{~s}$ for a period of 8 days to observe changes in performance. The removal efficiency fluctuated between 43 to $67 \%$ with an elimination capacity of around $70 \mathrm{~g} \mathrm{~m}^{-3} \mathrm{~h}^{-1}$. Despite the lower butanol concentrations in this period, high gas flow rates led to higher elimination capacities but lower removal efficiency compared with the lower gas flow rate.

Finally, during the last 5 days of operation, the EBRT was increased to $90 \mathrm{~s}$ and the butanol inlet concentration was rapidly increased to provide data on the maximum elimination capacity, which remained at approximately $100 \mathrm{~g} \mathrm{~m}^{-3} \mathrm{~h}^{-1}$.

It is noteworthy that the variation of gas flow rates led to a relatively low variation in the removal efficiency, suggesting that the gas to biofilm mass transfer was not significantly limiting. The rapid variations of the removal efficiency show the fast response of the BTF and the microorganisms to changing conditions. Since the BTF was challenged with higher loading rates of butanol, most of the time the efficiency ranged between 50 and $90 \%$.

The elimination capacity is plotted as a function of the mass loading rate in Figure 3. Similar to most biological reactor operations, the relationship is linear (i) up to a critical substrate mass loading rate (between 80 and $100 \mathrm{~g} \mathrm{~m}^{-3} \mathrm{~h}^{-1}$ ), after which elimination capacity approaches a maximum value of $100 \mathrm{~g} \mathrm{~m}^{-3} \mathrm{~h}^{-1}$ asymptotically (ii), where it remains nearly constant and independent of the mass loading rate.

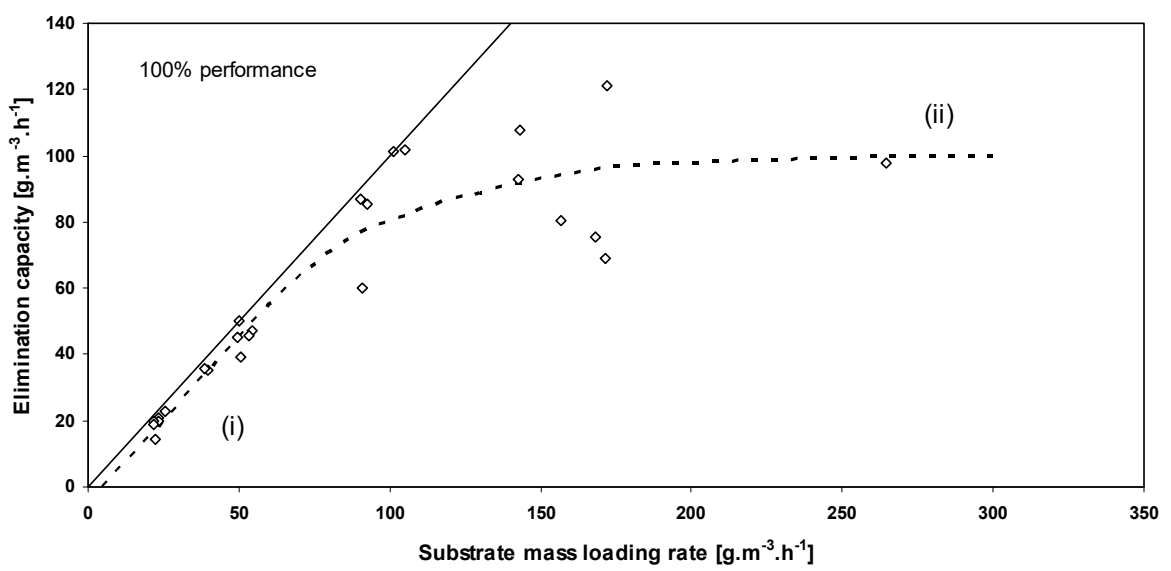

Figure 3. Effect of butanol mass loading rate on the elimination capacity of the BTF, showing (i) a linear region, and (ii) asymptotic approach to the maximum elimination capacity.

Figure 2 also shows the effect of the inlet concentration of 1-butanol on the elimination capacity and removal efficiency. Removal efficiency exceeded $80 \%$ for 1 -butanol inlet concentrations up to $1.2 \mathrm{~g} \mathrm{~m}^{-3}$ but generally diminished with concentrations beyond this value. This range of butanol concentration can be considered as a safe operating regime. Jorio et al. [15] suggested that identifying a safe range of operation is crucial for long-term performance and can be helpful in monitoring stability and operation.

\subsection{Evolution of the Pressure Drop}

Nutrient supplementation was carried out twice during the operation of the BTF to maintain performance, at days 27 and 40 . The additional nutrients tended to correlate with the removal efficiency, 
as can be observed in Figure 2. At day 27, the nutrient solution was supplied at a constant flow rate of $0.277 \mathrm{~m}^{3} \mathrm{~h}^{-1}$. The BTF attained a high removal efficiency of 86 to $93 \%$ between days 30 and 35, compared with efficiencies between 7 and $13 \%$ for the prior 15 days. After a while, the nutrient solution was consumed and removal efficiency decreased.

Visually, excessive accumulation of biomass on the perlite was observed as well as an increasing pressure drop after each application of nutrients (Figure 4), with the result being a partial clogging of the filter bed. If nutrient supply and concentration will, to some extent, improve the elimination capacity of a biological reactor, it will nevertheless also enhance microbial growth and initiate a pressure drop increase, as observed in the experiment. A reasonable pressure drop is crucial for optimal performance of the biotrickling filter because it directly impacts the energy required to drive air through the bioreactor, which is a substantial part of the operating costs. A long-term pressure drop under the recommended value of $700 \mathrm{~Pa} \mathrm{~m}^{-1}$ packing material is suggested [6], but in Figure 5 it can be seen that the pressure drop exceeded $8000 \mathrm{~Pa} \mathrm{~m}^{-1}$, at which point the experiment had to be discontinued. Potential methods, such as backwashing, for removing excess biomass in biotrickling filters have been identified and discussed [8] but could not be implemented with the available equipment in this work.

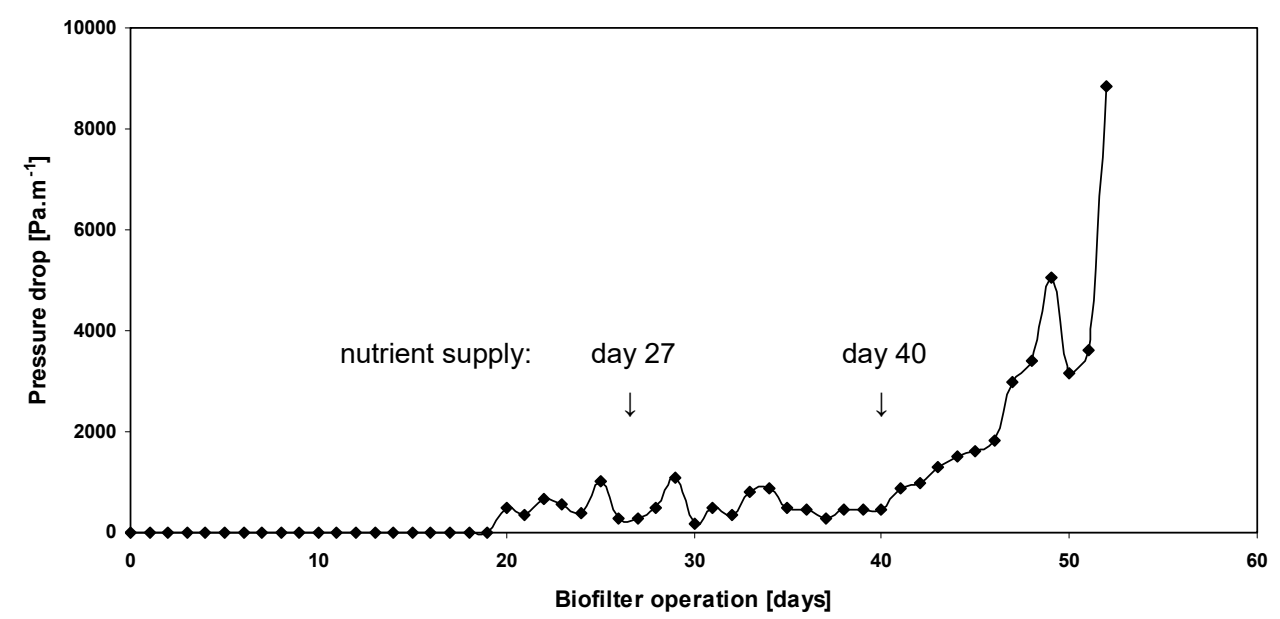

Figure 4. Profile of pressure drop across the bed height during BTF operation.

\section{3. $\mathrm{CO}_{2}$ Production}

In a biological air treatment process most VOCs are aerobically degraded to water, carbon dioxide, and biomass with an approximate formula of $\mathrm{C}_{5} \mathrm{H}_{7} \mathrm{NO}_{2}$ [27]. Hence, another method employed for monitoring biotrickling filter performance and acquiring information on the extent of mineralization is based on the measurement of $\mathrm{CO}_{2}$ concentrations in the inlet and outlet air streams. For this purpose, the $\mathrm{CO}_{2}$ production rate was calculated and the results are shown in Figure 5 illustrating a linear relationship between $\mathrm{CO}_{2}$ production rate and elimination capacity, confirming previous observations [28]. If all carbon coming from butanol degradation was mineralized to $\mathrm{CO}_{2}$, the slope observed on such a plot should be approximately 2.38 since for every mole of butanol degraded (74 g), 4 moles (176 g) of $\mathrm{CO}_{2}$ would be produced, according to stoichiometry.

From Figure 5, the slope was estimated to be $1.09\left(R^{2}=0.72\right)$, which is much lower than the stoichiometric value of 2.38 , indicating that a substantial proportion of organic carbon was incorporated into various components of microbial biomass and/or used for cellular maintenance and by-product formation. Although 1-butanol is somewhat soluble in water, analysis of the recirculating water failed to detect any significant amounts in that phase. 


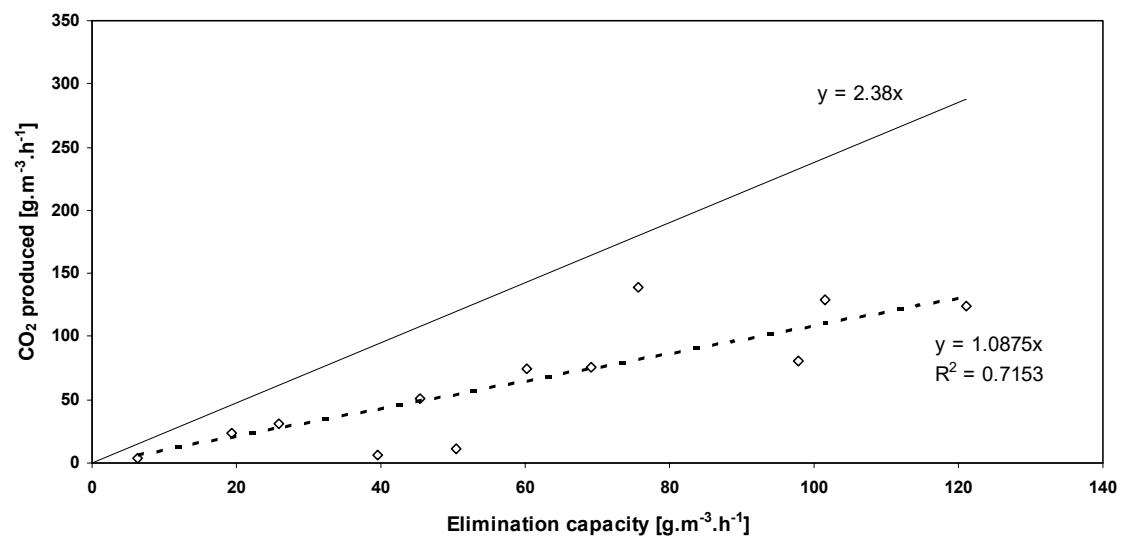

Figure 5. $\mathrm{CO}_{2}$ produced as a function of the butanol elimination capacity, compared to the theoretical relationship (slope 2.38) with complete and stoichiometric conversion.

From the data, it can be estimated that about $46 \pm 10 \%$ of the removed butanol was converted into $\mathrm{CO}_{2}$, corresponding to a carbon recovery of $0.46 \mathrm{~mol} \mathrm{CO} / \mathrm{mol} \mathrm{C}$, which is relatively low compared to values reported by Grove et al. [16]. Assuming that the missing carbon is all converted to biomass with the formula $\mathrm{C}_{5} \mathrm{H}_{7} \mathrm{NO}_{2}$ [16], the biomass yield would be $1.04 \mathrm{~g}$ biomass $/ \mathrm{g} \mathrm{C}$ which is likewise high compared to the suggested range of 0.17 to $0.43 \mathrm{~g}$ biomass/g C [16]. However, since the biofilter was operated in a biotrickling mode with $\mathrm{pH}$ control and nutrient supplementation, it is feasible that higher biomass growth yields were achieved in comparison to Grove et al. [16] who examined yields in a conventional biofilter (i.e., without liquid flow). In comparison, Kim and Sorial [27] measured biomass yields in biotrickling filters of 0.64 and $0.94 \mathrm{~g}$ biomass/g substrate for MEK and MIBK, respectively, which compares well with this work ( $0.67 \mathrm{~g}$ biomass $/ \mathrm{g}$ butanol).

\subsection{Comparisons of Performance}

A literature overview on alcohol VOCs removal under similar conditions was done to compare the elimination capacities, as shown in Table 1. During operation, the elimination capacity of the filter bed varied, approximately, between 10 and a maximum of $120 \mathrm{~g} \mathrm{~m}^{-3} \mathrm{~h}^{-1}$. Over the longer-term, a stable maximum elimination capacity of approximately $100 \mathrm{~g} \mathrm{~m}^{-3} \mathrm{~h}^{-1}$ was achieved. Results for the removal of butanol under similar conditions are relatively uncommon in the literature, but the measured elimination capacity $\left(100 \mathrm{~g} \mathrm{~m}^{-3} \mathrm{~h}^{-1}\right)$ is comparable to those few previously reported (102 to $160 \mathrm{~g} \mathrm{~m}^{-3} \mathrm{~h}^{-1}$ ) and for other short chain alcohol VOCs. Wang et al.'s result of $317 \mathrm{~g} \mathrm{~m}^{-3} \mathrm{~h}^{-1}$ stands out [22], but their air included butyl acetate and phenylacetic acid, and some potential interactions were noted when inhibitory effects were examined.

Table 1. Performance comparison between this work and selected other studies on $\mathrm{C} 1$ to $\mathrm{C} 4$ alcohols using biofilters or biotrickling filters.

\begin{tabular}{cccc}
\hline Type of Process & Type of VOC & Elimination Capacity $\mathbf{( \mathbf { ~ m } ^ { \mathbf { - 3 } } \mathbf { h } \mathbf { - 1 } )}$ & Reference \\
\hline Biofilter & Ethanol & $53-219$ & {$[29]$} \\
Biofilter & Methanol & 113 & {$[29]$} \\
Biofilter & Ethanol & 195 & {$[9]$} \\
Biotrickling & Methanol & 1916 & {$[29]$} \\
Biofilter & n-Butanol and sec-butanol & 56 and 21 & {$[11]$} \\
Biofilter & Methanol & 250 & {$[30]$} \\
Biotrickling & Butanol & 102 & {$[17]$} \\
Biofilter & Butanol (transient) & 131 & {$[21]$} \\
Biofilter + biotrickling & Butanol (in mixture) & 2 & {$[19]$} \\
Biofilter & Butanol & 162 & {$[31]$} \\
Biotrickling & Butanol (in mixture) & 317 & {$[22]$} \\
Biotrickling & Butanol & 100 & This work \\
\hline
\end{tabular}

VOC: Volatile Organic Compound. 


\section{Conclusions}

The laboratory-scale perlite-packed biotrickling filter was operated successfully for a period of 60 days, demonstrating effective and efficient removal from air for higher butanol concentrations than have been commonly reported (up to $4.65 \mathrm{~g} \mathrm{~m}^{-3}$ ) with a maximum elimination capacity of $100 \mathrm{~g} \mathrm{~m}^{-3} \mathrm{~h}^{-1}$. After exceeding butanol inlet concentrations of $4 \mathrm{~g} \mathrm{~m}^{-3}$, the removal efficiency rapidly dropped from 90 to $15 \%$, indicating an inhibition effect. Butanol concentrations up to approximately $1.2 \mathrm{~g} \mathrm{~m}^{-3}$ can be considered as a safe operating region since removal efficiencies were stable and above $80 \%$. Carbon dioxide production was shown to correlate well with the pollutant removal. Nutrient supplementation improved the elimination capacity, but it resulted in excess biomass growth and rising pressure drop. To prevent an increase of pressure drop resulting from biomass overgrowth, a lower and controlled level of nutrient supplementation or biomass removal will need to be examined for this potential industrial application.

Acknowledgments: This work was funded by the Natural Sciences and Engineering Research Council of Canada through the Engage Grants program.

Author Contributions: The authors jointly conceived and designed the experiments. Thomas Schmidt performed the experiments, data analysis, and wrote a preliminary version of the manuscript. William A. Anderson provided technical guidance and oversight at all stages and wrote the final versions of the paper.

Conflicts of Interest: The authors declare no conflict of interest. The funding sponsors had no role in the design of the study; in the collection, analyses, or interpretation of data; in the writing of the manuscript, and in the decision to publish the results.

\section{References}

1. Bartacek, J.; Kennes, C.; Lens, P.N.L. Biotechniques for Air Pollution Control; Taylor \& Francis Group: Abingdon, UK, 2010.

2. Cooper, C.D.; Alley, F.C. Air Pollution Control: A Design Approach, 3rd ed.; Waveland Press Inc.: Long Grove, IL, USA, 2002.

3. Borwankar, D.S.; Anderson, W.A.; Fowler, M.W. A technology assessment tool for evaluation of VOC abatement technologies from solvent based industrial coating operations. In Air Quality-New Perspective; Badilla, G.L., Valdez, B., Schorr, M., Eds.; InTech Open: Rijeka, Croatia, 2016.

4. Iranpour, R.; Cox, H.H.; Deshusses, M.A.; Schroeder, E.D. Literature review of air pollution control biofilters and biotrickling filters for odor and volatile organic compound removal. Environ. Prog. Sustain. Energy 2005, 24, 254-267. [CrossRef]

5. Delhoménie, M.C.; Heitz, M. Biofiltration of air: A review. Crit. Rev. Biotechnol. 2005, 25, 53-72. [CrossRef] [PubMed]

6. Mudliar, S.; Giri, B.; Padoley, K.; Satpute, D.; Dixit, R.; Bhatt, P.; Pandey, R.; Juwarkar, A.; Vaidya, A. Bioreactors for treatment of VOCs and odours-A review. J. Environ. Manag. 2010, 91, 1039-1054. [CrossRef] [PubMed]

7. Kennes, C.; Rene, E.R.; Veiga, M.C. Bioprocesses for air pollution control. J. Chem. Technol. Biotechnol. 2009, 84, 1419-1436. [CrossRef]

8. Schiavon, M.; Ragazzi, M.; Rada, E.C.; Torretta, V. Air pollution control through biotrickling filters: A review considering operational aspects and expected performance. Crit. Rev. Biotechnol. 2016, 36, 1143-1155. [CrossRef] [PubMed]

9. Arulneyam, D.; Swaminathan, T. Biodegradation of ethanol vapour in a biofilter. Bioprocess Eng. 2000, 22, 63-67. [CrossRef]

10. Chan, W.C.; Lin, Y.S. Compounds interaction on the biodegradation of butanol mixture in a biofilter. Bioresour. Technol. 2010, 101, 4234-4237. [CrossRef] [PubMed]

11. Chan, W.C.; Lai, Y.Z. Biodegradation kinetic behaviours of n-butyl alcohol and sec-butyl alcohol in a composite bead biofilter. Process Biochem. 2009, 44, 593-596. [CrossRef]

12. Kwon, H.M.; Yeom, S.H. Design of a Biofilter Packed with Crab Shell and Operation of the Biofilter Fed with Leaf Mold Solution as a Nutrient. Biotechnol. Bioprocess Eng. 2009, 14, 248-255. [CrossRef] 
13. Kam, S.K.; Kim, J.K.; Lee, M.G. Removal characteristics of mixed gas of ethyl acetate and 2-butanol by a biofilter packed with Jeju scoria. Korean J. Chem. Eng. 2011, 28, 1019-1022. [CrossRef]

14. Kibazohi, O.; Yun, S.I.; Anderson, W.A. Removal of hexane in biofilters packed with perlite and a peat-perlite mixture. World J. Microbiol. Biotechnol. 2004, 20, 337-343. [CrossRef]

15. Jorio, H.; Bibeau, L.; Heitz, M. Biofiltration of Air Contaminated by Styrene: Effect of Nitrogen Supply, Gas Flow Rate, and Inlet Concentration. Environ. Sci. Technol. 2000, 34, 1764-1771. [CrossRef]

16. Grove, J.A.; Zhang, H.; Anderson, W.A.; Moo-Young, M. Estimation of Carbon Recovery and Biomass Yield in the Biofiltration of Octane. Environ. Eng. Sci. 2009, 26, 1497-1502. [CrossRef]

17. Heinze, U.; Friedrich, C.G. Respiratory activity of biofilms: Measurement and its significance for the elimination of n-butanol from waste gas. Appl. Microbiol. Biotechnol. 1997, 48, 411-416. [CrossRef]

18. Fitch, M.W.; England, E.; Zhang, B. 1-Butanol removal from a contaminated airstream under continuous and diurnal loading conditions. J. Air Waste Manag. Assoc. 2002, 52, 1288-1297. [CrossRef] [PubMed]

19. Lee, S.H.; Li, C.; Heber, A.J.; Ni, J.; Huang, H. Biofiltration of a mixture of ethylene, ammonia, n-butanol, and acetone gases. Bioresour. Technol. 2013, 127, 366-377. [CrossRef] [PubMed]

20. Ondarts, M.; Hort, C.; Sochard, S.; Platel, V.; Moynault, L.; Seby, F. Evaluation of compost and a mixture of compost and activated carbon as biofilter media for the treatment of indoor air pollution. Environ. Technol. 2012, 33, 273-284. [CrossRef] [PubMed]

21. Feizi, F.; Nasernejad, B.; Zamir, S.M. Effect of operating temperature on transient behaviour of a biofilter treating waste-air containing n-butanol vapor during intermittent loading. Environ. Technol. 2016, 37, 1179-1187. [CrossRef] [PubMed]

22. Wang, Q.H.; Zhang, L.; Tian, S.; Sun, P.T.-C.; Xie, W. A pilot-study on treatment of a waste gas containing butyl acetate, n-butyl alcohol and phenylacetic acid from pharmaceutical factory by bio-trickling filter. Biochem. Eng. J. 2007, 37, 42-48. [CrossRef]

23. Liu, S.; Qureshi, N. How microbes tolerate ethanol and butanol. New Biotechnol. 2009, 26, 117-121. [CrossRef] [PubMed]

24. Kennes, C.; Veiga, M.C. Bioreactors for Waste Gas Treatment; Kluwer Academic Publishers: Dordrecht, The Netherlands, 2001.

25. Estrada, J.M.; Quijano, G.; Lebrero, R.; Munoz, R. Step-feed biofiltration: A low cost alternative configuration for off-gas treatment. Water Res. 2013, 47, 4312-4321. [CrossRef] [PubMed]

26. Sorial, G.A.; Smith, F.L.; Suidan, M.T.; Pandit, A.; Biswas, P.; Brenner, R.C. Evaluation of trickle-bed air biofilter performance for styrene removal. Water Res. 1998, 32, 1593-1603. [CrossRef]

27. Kim, D.; Sorial, G.A. Nitrogen utilization and biomass yield in trickle bed air biofilters. J. Hazard. Mater. 2010, 182, 358-362. [CrossRef] [PubMed]

28. Rene, E.R.; López, M.E.; Veiga, M.C.; Kennes, C. Performance of a fungal monolith bioreactor for the removal of styrene from polluted air. Bioresour. Technol. 2010, 101, 2608-2615. [CrossRef] [PubMed]

29. Kennes, C.; Thalasso, F. Waste Gas Biotreatment Technology. J. Chem. Technol. Biotechnol. 1998, 72, $303-319$. [CrossRef]

30. Mohseni, M.; Allen, D.G. Biofiltration of mixtures of hydrophilic and hydrophobic volatile organic compounds. Chem. Eng. Sci. 2000, 55, 1545-1558. [CrossRef]

31. Eshraghi, M.; Parnian, P.; Zamir, S.M.; Halladj, R. Biofiltration of n-butanol vapor at different operating temperatures: Experimental study and mathematical modeling. Int. Biodeterior. Biodegrad. 2017, 119, 361-367. [CrossRef]

(C) 2017 by the authors. Licensee MDPI, Basel, Switzerland. This article is an open access article distributed under the terms and conditions of the Creative Commons Attribution (CC BY) license (http:/ / creativecommons.org/licenses/by/4.0/). 